\title{
Describing the possible climate changes in France and some examples of their effects on main crops used in livestock systems
}

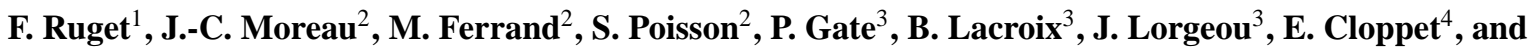 \\ F. Souverain 4 \\ ${ }^{1}$ INRA, UMR 1114 EMMAH, 84914 Avignon cedex 9, France \\ ${ }^{2}$ Institut de l'Élevage, Auzeville 31326 Castanet-Tolosan et 149 Rue de Bercy 75011, Paris, France \\ ${ }^{3}$ Arvalis Institut du végétal, La Minière 78210 Guyancourt/31450 Baziège/91170 Boigneville, France \\ ${ }^{4}$ Météo-France, 42 Av G Coriolis 31000 Toulouse, France
}

Received: 31 December 2009 - Revised: 13 July 2010 - Accepted: 14 July 2010 - Published: 2 August 2010

\begin{abstract}
The effects of climate change on forage and crop production are an important question for the farmers and more largely for the food security in the world. Estimating the effect of climate change on agricultural production needs the use of two types of tools: a model to estimate changes in national or local climates and an other model using climatic data to estimate the effects on vegetation. In this paper, we will mainly present the effects of climate change on climatic features, the variability of criteria influencing crop production in various regions of France and some possible effects on crops.
\end{abstract}

\section{Introduction}

The effects of greenhouse effect increase on future climate are assessed through GCM (General circulation model). We have used the outputs from one of them, the ARPEGE model developed by the CNRM (Météo-France) with the input of two scenarios of economic, technical and socio-economic development. These are the A 2 scenario, with weak attention to $\mathrm{GHG}$ emissions leading to a high $\mathrm{CO}_{2}$ concentration in the atmosphere at the end of the century $(800 \mathrm{ppm})$ and the B1 scenario, a moderate scenario where the $\mathrm{CO}_{2}$ concentration would be better controlled, allowing to reach only $550 \mathrm{ppm}$ at the end of the century.

As crop indicator, it is possible to use either a full crop model using sophisticated focused entries for elaborated outputs, like yields either specific inputs for agroclimatic indicators, referring to some specific, especially sensitive, periods or processes. We will use both types of tools to obtain either information on crop chances to get over some difficult phases, either range of achievable yields.

The aim of this study is to estimate projected changes for main agricultural areas at the regional scale.

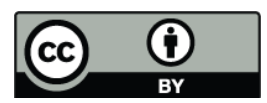

Correspondence to: F. Ruget

(ruget@avignon.inra.fr)

\section{Material and methods}

We have performed three types of analyses using the present and future climatic data. First, we analyzed the climatic data, with means, maps and multiple factor analysis. Second, we built and tested several agrometeorological criteria, in order to analyze the evolution of these criteria, and know the risks on practices for the main crops in livestock farms. Third, we used meteorological data to provide inputs for a crop model for grass, alfalfa (grass and legumes forages) and maize (representative summer arable crop in France), and we estimated the projected evolution of yields and water needs, without or with simple adaptations of agricultural practices.

\subsection{Data, tools}

\subsubsection{GCM (general circulation model)}

As GCM, we chose ARPEGE, from Météo-France for many reasons: it is one of the GCM used in the IPCC AR4, it has similar results with other GCM (Pérarnaud et al., 2005; Planton et al., 2008) and it has a variable resolution over the world, higher in our study zone, reaching 50 to $60 \mathrm{~km}$ over France (Déqué, 2007). Moreover, Déqué (2007) proposed regionalization methods to fit better with local conditions.

Our study has focused on two time periods, the near (2020-2049) and the distant (2070-2099) future. For each 
of them, we have only considered mean effect, without any attempt to catch the temporal evolution inside each period. Since the climatic results are similar in the near future for both scenarios, and they have the same tendencies in the distant future, which induces the higher impacts, we chose to only present here the results of the distant future for the scenario A2.

\subsubsection{Use of meteorological data: RCM (regional climate model)}

According to the aim of the parts of the study, we used different downscaling methods. For the two first parts (climate description and agrometeorological indices), we used direct outputs of the high-resolution GCM because they are convenient for studies on the frequency of events (for instance extreme events, like very high temperatures) or important thresholds for crop management (number of days without rain in spring for entering in the field or in summer for preventing drought effects. The study was performed with 235 points in the metropolitan France $\left(50 \times 50 \mathrm{~km}^{2}\right.$ grid),

For the third part (use of a crop model), we used variations between the present and the future estimated climatic values, so-called anomalies. It is the delta method proposed by Déqué (2007) and used in the same case by Bergot et al. (2004) or Gonzalez-Camacho et al. (2008). This choice was justified by the existence of significant differences between computed yield (mean and standard error) when directly using observed and estimated series in the present (Gonzalez-Camacho et al., 2008).

According to Déqué (2007), "this method needs observed daily data at the location of the study. It also assumes that the climate variability is unchanged in the scenario projection, i.e. is inherited from observed variability". In order to obtain pairs of actual and fictive stations, we chose 34 meteorological stations in the main agricultural areas, associating actual stations and centre of grids, as near as possible in distance and above all on altitude. The anomalies (ratio for rain, differences for other variables) were computed as 30 days moving averages for all the available years for each period of the future.

\subsubsection{Crop model}

The crop model STICS was designed at the end of the nineties to estimate yield and needs (water, nitrogen) of main arable crops and pastures (Brisson et al., 1998; Ruget et al., 2006). It has been validated in a large range of situations in France (Brisson et al., 2002; Ruget et al., 2006; Ruget, 2009) : in these studies, yields and water consumption have been correctly estimated in a wide range of climates (especially temperature) and with various levels of irrigation (arable crops) and fertilisation (grassland).

\subsection{Methods}

\subsubsection{Climatic data, univariate and multivariate analysis}

After mapping several climatic variables, we performed a multiple factor analysis (MFA) applied on spatial data in order to reach a global description of the climate and not independently on each variable (Lebart et al., 1995; Escoffier and Pagès, 1998; Ferrand et al., 2008). We analyzed 7 climatic variables (minimum and maximum temperature, rain, solar radiation, PET, wind, humidity) and an extra bloc containing the spatial coordinates. We used 7 rank statistics, that is, for each series of 30 years (except 37 years for the recent past period, hereafter named present) of each variable, the 7 values showing the distribution (median, minimum and maximum, 5th and 95th, 25th and 75th percentiles) for each series of climatic data corresponding to a time period (present or future), This allows the delimitation of zones having similar climates. In this way, MFA was used to define climatic zones in each period by using the future as reference. That means that we used criteria of zones defined for the distant future and we applied the criteria defining the zones for distant future to the present in order to see where the zones of the future are present now, and where new types of climates will appear.

\subsubsection{Agroclimatic indicators}

The second method used is the definition of agroclimatic indices and the comparison of values in the present and in a future period. The aim of using indicators is to give indications on specific periods of the year when crops might be affected by harsh climatic conditions: for instance, the occurrence of very low temperatures in spring, or very high temperatures in some consecutive days. We used pre-established and ownbuilt indicators. Although some indicators are not specific for a period of the plant cycle, the effects on crop are often connected to the sensitive phases of the crops.

The frequency of sequences of 5 days with more than $60 \mathrm{~mm}$ of rain in spring preventing the beginning of grazing is one example combining field conditions (high rainfall estimating low soil portability) and period of production (heat sums after the beginning of growth).

For wheat, we used MFA to study the risks of wheat grain shrivelling. MFA allows the combination of several variables: the percentiles of number of days (or consecutive days) higher than thresholds of minimum and maximum temperatures and percentiles of the number of days of water deficit, known as factors stopping partially or totally grain filling. Among these criteria, we have used the number of days with maximum temperatures higher than $25^{\circ} \mathrm{C}$ where begins the decrease of grain filling and the number of days with maximum temperature higher than $30^{\circ} \mathrm{C}$ where grain filling is stopped. A high number of consecutive days with temperature higher than the threshold may stop definitely grain growth. MFA identifies zones with the same risk of grain shrivelling. They are defined as 7 classes with the 

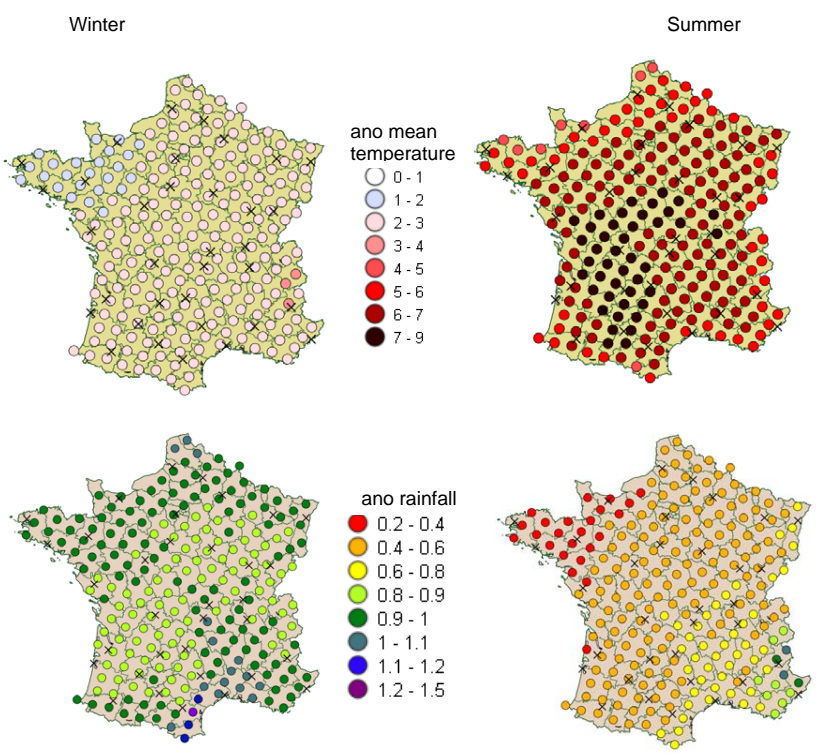

Figure 1. Seasonal anomalies for temperature and rainfall in the distant future (A2 scenario) in winter and summer: mean values of differences (future-present) for temperature(in ${ }^{\circ} \mathrm{C}$ ), ratio (future/present) for rainfall (no change $=1$ ) for the season.

present climatic data and the same criteria are applied on the future climatic data.

For maize, the risk of stopping grain filing was only studied through the frequency of one variable 1 day with maximum temperature higher than $38^{\circ} \mathrm{C}$.

\subsubsection{Use of the crop model}

The third method is the estimation of achievable yields, taking into account future climate. We present only one example on pastures. We assumed slight adaptations of practices, like the dates of mowing (or grazing), which are automatically adapted using lengths between uses expressed in heat sums.

\section{Results}

\subsection{Climatic data}

\subsubsection{Univariate analysis}

An important result of this study is the confirmation of higher temperatures and evaporation conditions, together with lower rainfall for the whole French territory. In Fig. 1a (temperature) and b (rainfall), it appears that climate is more affected in summer than in the other seasons, not only for temperature but also for rainfall.

For temperatures, the highest increase is predicted in summer to the western surround of the Massif Central (more than $7{ }^{\circ} \mathrm{C}$ for mean temperature in distant A2). The lower increases are in Brittany and Normandy both in summer and winter.

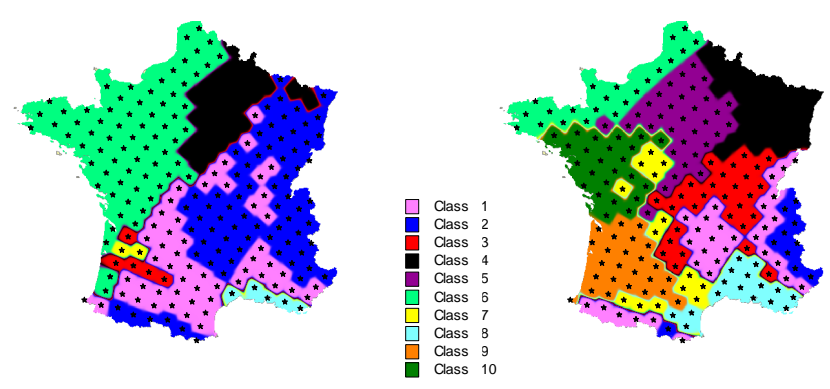

Figure 2. Climatic zones as defined by Multiple factor analysis (MFA) on spatial data: left, classes defined in the distant future applied on the present data, right classes as defined in the distant future.

For rainfall, the differences of the climate evolution between regions are high: some regions are slightly affected like Alps and South-East, while others are highly affected and they might lose $60 \%$ of their present summer rain. The zone with the highest decrease of rain in summer is the North-West part of France, mainly Normandy and Brittany.

\subsubsection{Multivariate analysis}

In the Fig. 2, we show the present situations of 10 zones defined by using the MFA of spatial data in the distant future climate. It can be seen that the zone of low mountain climates will go up, the extension of high mountain climate will be reduced, while the area of the Mediterranean climate will be larger. The Atlantic front will be dryer: 3 new types of climate will appear in the western part of France (except Brittany, Normandy and North on one hand and Pyrenees mountains on the other hand). The mean climatic characteristics of these zones are not far from those of the Mediterranean zone means (higher maximal temperatures and high evapotranspiration), but with higher rainfall and lower solar radiation.

\subsection{Agro-climatic indicators}

\subsubsection{Grassland}

In Fig. 3, showing the difference of the number of days with unfavourable conditions for grazing when production is sufficient $\left(500^{\circ} \mathrm{C}\right.$.day after the possible beginning of growth), conditions will benefit from an improvement in springtime in most cases, and especially in the South-East zone of France. Only a small area in the North appears to be faced to worsened conditions.

\subsubsection{Winter wheat}

The Table 1 shows the number of days with maximum temperature higher than $25^{\circ} \mathrm{C}$ during a period of $650^{\circ} \mathrm{C}$ after 5 June for each defined class, that is for each geographical zone in the present and the future: assuming that the 
Table 1. Number of days where $T_{\max }>25^{\circ} \mathrm{C}$ for the 7 defined classes (classes defined on the present period), applied on present and future data, ear emergence at 5 June (like in the present conditions).

\begin{tabular}{ccccc|cccc}
\hline & \multicolumn{3}{c}{$\begin{array}{c}1970-2006 \\
\text { number of days where } T_{\max }>25^{\circ} \mathrm{C}\end{array}$} & \multicolumn{4}{c}{$\begin{array}{c}2070-2099 \\
\text { number of days where } T_{\max }>25^{\circ} \mathrm{C}\end{array}$} \\
\hline & mean & standard error & minimum & maximum & mean & standard error & minimum & maximum \\
\hline Class 1 & 5.4 & 2 & 1.2 & 9.9 & 9.9 & 4.2 & 4.4 & 15.5 \\
Class 2 & 2.1 & 1.7 & 0 & 5.4 & 2.7 & 2.5 & 0.1 & 7.4 \\
Class 3 & 5.9 & 2.3 & 1.5 & 9.7 & 14.6 & 1.9 & 11.8 & 16.1 \\
Class 4 & 11.2 & 3.6 & 3.1 & 17.4 & 18 & 3.8 & 8 & 25.4 \\
Class 5 & 10.3 & 4.3 & 3.7 & 19.5 & 16.9 & 2.7 & 13.2 & 22.6 \\
Class 6 & 13 & 3.6 & 5.3 & 15.9 & 24.8 & 5.4 & 7.6 & 36.2 \\
Class 7 & 24.8 & 5.4 & 13.4 & 31.5 & 27.8 & 5.7 & 14.5 & 34.1 \\
\hline
\end{tabular}

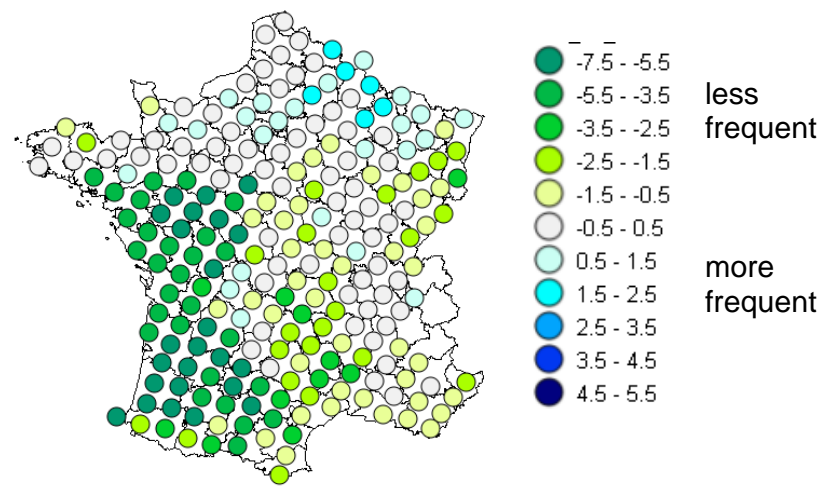

Figure 3. Agro-climatic indicator for the decrease of soil trafficability for early grazing, defined as 5 days with rainfall higher than $60 \mathrm{~mm}$ at the beginning of spring $\left(500^{\circ} \mathrm{C}\right.$.day after $1 \mathrm{Febru}-$ ary). Number of years among 10 when more (positive values) or less (negative values) unfavourable conditions will occur in the distant A2 scenario.

ear emerges at 5 June, it illustrates the number of days with shrivelling risks in the classes defined with present climatic data.

Class 2 has very low risk now, and the mean value of this criterion is higher in the future. In the same way, classes 1 and 3 with low risk now will have higher risk later. Moreover (Fig. 4), these zones will become very small in the future. Class 6 will have the greatest increase - from extreme SouthWest to almost the half western part of France - and it is a class with high shrivelling risks. That means that without any management adaptation, the risks of poor grain filling will become high: choosing varieties with earlier ear emergence may allow to avoid high temperatures during grain filling.

\subsubsection{Maize}

In Fig. 5, the number of days with maximum temperature higher than $38^{\circ} \mathrm{C}$ will greatly increase between the present

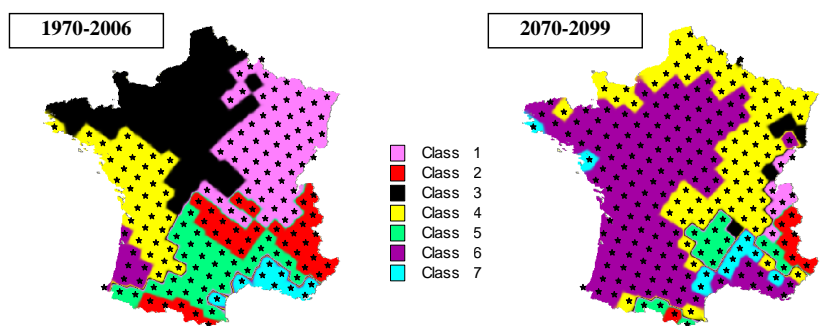

Figure 4. Risks of wheat shrivelling, using the MFA method to define zones. Left, definition of zones with present climatic data. Right, application to the future of the criteria defined in the present (distant A2 scenario).

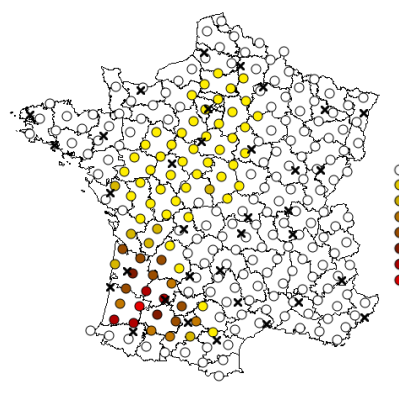

Present

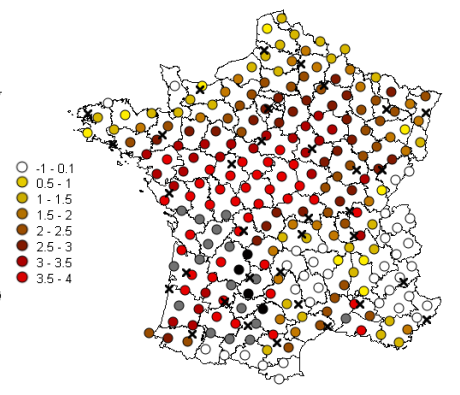

Distant A2
Figure 5. Indicator of risks for maize grain filling: difference of number of years among 10 with at least once a maximum temperature higher than $38^{\circ} \mathrm{C}$ in the first half August, between the future (distant A2) and the present period, that is increase in the risk when positive values.

period (left) and the distant future period (right, distant A2). Now, the risk of stopping grain filling of maize is mainly present in the South-western part of France, but this event will occur in all the regions of France in the distant future.

For wheat and maize, heat risks during grain filling will increase in the future, because of the increase of temperatures. 


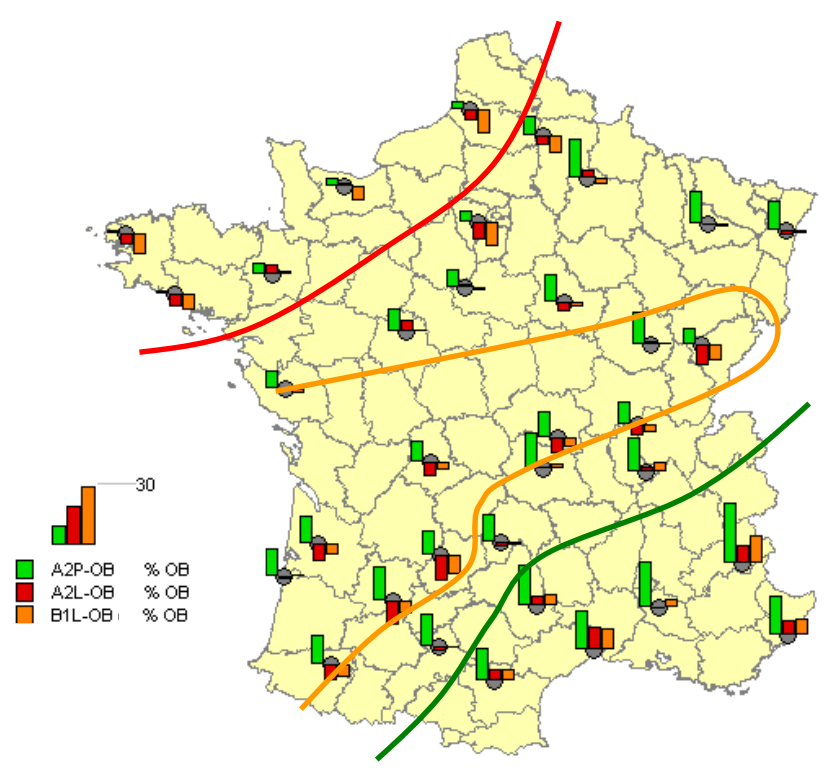

Figure 6. Grassland relative differences of yields between 3 future scenarios (A2P: near A2, green; A2L: distant A2, red; B1L: distant $\mathrm{B} 1$, orange) and present estimations (OB: observed) for 34 coupled actual and fictive stations.

That means that it will be essential to change practices (variety or cultivation dates) to avoid the risks of high fall of yield for temperature sensitive species.

\subsection{Yields computed by the crop model}

We show only one example of projected variation of yield, for grassland with frequent uses, cultivated on a soil with low available water (normal for grasslands) for all the studied scenarios (Fig. 6). Simulations take into account the positive $\mathrm{CO}_{2}$ effects (increase of production, decrease of transpiration (Ruget et al., 1996; Bethenod et al., 2001; Long et al., 2006)). The evolution is mostly positive in the near future (green bar) and generally slowly negative in the distant future, except in the South-East of France where the increase of production will likely continue in the second half of the century.

The increase in yields comes mainly from the higher temperatures (development acceleration, leaf growth increase), occurring without high decrease of water availability and taking advantage from the possible reduction of transpiration by $\mathrm{CO}_{2}$ increase. The decrease in the distant future comes from the lack of water, which seems not higher in the future than now in the South-East.

The comparison of grass and alfalfa in the same conditions shows an advantage of alfalfa, mainly due to the higher rooting depth avoiding water stress even in the distant future (Ruget et al., 2010).

\section{Conclusions}

In the climate analysis, apart from the confirmation of already known effects (higher temperature, lower precipitation), the most interesting result for agriculture comes from the spatial distribution of changes: all the regions of France are not affected in the same way. One interest of this study is also to show complementary and corroborating information from several analyses (univariate analyses, MFA on spatial data, agro-climatic indicators, and crop models).

The reliability of the chain through the use of meteorological data with a degree of uncertainty for elaborating criteria also affected by an other degree of uncertainty (thermal thresholds in agroclimatic indicators) or the filter of crop models is an open question.

Further work is needed to confirm and improve these conclusions, in order to be able to propose new adapted agricultural practices, especially when considering the system and farm levels.

Edited by: T. Cegnar

Reviewed by: B. Seguin and two other anonymous referees

\section{References}

Bergot, M., Cloppet, E., Pérarnaud, V., Déqué, M., Marçais, B., and Desprez-Loustau, M. L.: Simulation of potential range expansion of oak disease caused by Phytophthora cinnamomi under climate change, Glob. Change Biol., 10, 1539-1552, 2004.

Bethenod, O., Ruget, F., Katerji, N., Combe, L., and Renard, D.: Impact of atmospheric $\mathrm{CO}_{2}$ concentration on water use efficiency of maize, Maydica, 46, 2, 75-80, 2001.

Brisson, N., Mary, B., Ripoche, D., Jeuffroy, M. H., Ruget, F., Nicoullaud, B., Gate, P., Devienne-Barret, F., Antonioletti, R., Dürr, C., Richard, G., Beaudoin, N., Recous, S., Tayot, X., Plénet, D., Cellier, P., Machet, J.-M., Meynard, J. M., and Delécolle, R.: STICS : a generic model for the simulation of crops and their water and nitrogen balances. I. Theory and parametrization applied to wheat and corn, Agronomie, 18, 311346, 1998.

Brisson, N., Ruget, F., Gate, P., Lorgeou, J., Nicoullaud, B., Tayot, X., Plénet, D., Jeuffroy, M.-H., Bouthier, A., Ripoche, D., Mary, B., and Justes, E.: STICS: a generic model for the simulation of crops and their water and nitrogen balances. II. Model validation for maize and wheat, Agronomie, 22, 69-92, 2002.

Déqué, M.: Frequency of precipitation and temperature extremes over France in a anthropogenic scenario: Model results and statistical correction according to observed values, Global Planet. Change, 57, 16-26, 2007.

Escoffier, B. and Pagès, J.: Analyses factorielles simples et multiples, DUNOD, Paris, 284 pp., 1998.

Ferrand, M., Lequenne, D., Manneville, V., Jannot, P., and Lopez C.: Apport de la spatialisation des données en analyse multidimensionnelle pour évaluer l'impact des activités agricoles sur la teneur en nitrates des eaux, Revue MODULAD, 39, 81-94, 2008.

Gonzalez-Camacho, M., Mailhol, J.-C., and Ruget, F.: Impacts locaux attendus de l'augmentation du $\mathrm{CO}_{2}$ dans l'atmosphère sur 
la productivité de l'eau du maïs dans la Drôme, France, Irrigation and Drainage, 57, 2, 229-243, Published Online: 27 July 2007, online ISSN: 1531-0361, doi:10.1002/ird.332, 2008.

IPCC: Climate Change: The Physical Science Basis. Contribution of Working Group I to the Fourth Assessment, Report of the Intergovernmental Panel on Climate Change, Cambridge University Press, Cambridge, United Kingdom and New York, NY, USA, 2007, 996 pp., 2007.

Lebart, L., Morineau, A., and Piron, M.: Statistique Exploratoire Multidimensionnelle, DUNOD, Paris, 439 pp., 1995.

Long, S., Ainsworth, E., Leakey, A., Nösberger, J., and Ort, D.: Food for Thought: Lower-Than-Expected Crop Yield Stimulation with Rising $\mathrm{CO}_{2}$ Concentrations, Science, 312, 1918-1921, 2006.

Pérarnaud, V., Seguin, B., Malezieux, E., Déqué, M., and Loustau, D.: Agrometeorological research and applications needed to prepare agriculture and forestry to 21 st century Climate Change, Climatic Change, 70, 319-340, 2005.

Planton, S., Déqué, M., Chauvin, F., and Terray, L.: Expected impacts of climate change on extreme climate events, C. R. Geoscience, 340, 564-574, 2008.
Ruget, F., Bethenod, O., and Combe, L.: Repercussions of increased atmospheric $\mathrm{CO}_{2}$ on maize morphogenesis and growth for various temperature and radiation levels, Maydica, 41, 3, 181-191, 1996.

Ruget, F., Novak, S., and Granger, S.: Du modèle STICS au système ISOP pour estimer la production fourragère, Adaptation à la prairie, application spatialisée, Fourrages, 186, 241-256, 2006.

Ruget, F.: Impact du changement climatique sur la luzerne et la prairie, disparités régionales, in: Changement climatique, Conséquences et enseignements pour les grandes cultures et l'élevage herbivore, 22 octobre 2009, Paris, Arvalis-Institut du Végétal Ed, 2009.

Ruget, F., Moreau, J.-C., Cloppet, E., and Souverain, F.: Effect of climate change on grassland production for herbivorous livestock systems in France, in: Grassland in a changing world, edited by: Schnyder, H., Isselstein, J., Taube, F., Schellberg, J., Wachendorf, M., Herrmann, A., Gierus, M., Auerswald, K., Wrage, N., and Hopkins, A., Grassland Science in Europe, Vol. 15, EGF 2010, Kiel, in press, 2010. 